Author affiliations and support information (if applicable) appear at the end of this article.

Published at jco.org on November 21, 2017

Written on behalf of the CROSS study group.

Clinical trial information: NTR487 (Netherlands Trial Register)

Corresponding author: Bo Jan Noordman, MD, Department of Surgery, Erasmus MC-University Medical Center, PO Box 2040, 3000 CA Rotterdam, the Netherlands; e-mail: b.noordman@ erasmusmc.nl.

(C) 2017 by American Society of Clinical Oncology

0732-183X/18/3603w-268w/\$20.00

\title{
Effect of Neoadjuvant Chemoradiotherapy on Health-Related Quality of Life in Esophageal or Junctional Cancer: Results From the Randomized CROSS Trial
}

Bo Jan Noordman, Mathilde G.E. Verdam, Sjoerd M. Lagarde, Maarten C.C.M. Hulshof, Pieter van Hagen, Mark I. van Berge Henegouwen, Bas P.L. Wijnhoven, Hanneke W.M. van Laarhoven, Grard A.P. Nieuwenhuijzen, Geke A.P. Hospers, Johannes J. Bonenkamp, Miguel A. Cuesta, Reinoud J.B. Blaisse, Olivier R. Busch, Fiebo J.W. ten Kate, Geert-Jan M. Creemers, Cornelis J.A. Punt, John Th.M. Plukker, Henk M.W. Verheul, Ernst J. Spillenaar Bilgen, Herman van Dekken, Maurice J.C. van der Sangen, Tom Rozema, Katharina Biermann, Jannet C. Beukema, Anna H.M. Piet, Caroline M. van Rij, Janny G. Reinders, Hugo W. Tilanus, Ewout W. Steyerberg, Ate van der Gaast, Mirjam A.G. Sprangers, and J. Jan B. van Lanschot

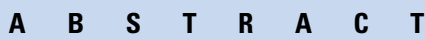

\section{Purpose}

To compare pre-agreed health-related quality of life (HROOL) domains in patients with esophageal or junctional cancer who received neoadjuvant chemoradiotherapy (nCRT) followed by surgery or surgery alone. Secondary aims were to examine the effect of nCRT on HRQOL before surgery and the effect of surgery on HRQOL.

\section{Patients and Methods}

Patients were randomly assigned to nCRT (carboplatin plus paclitaxel with concurrent 41.4-Gy radiotherapy) followed by surgery or surgery alone. HRQOL was measured using the European Organisation for Research and Treatment of Cancer Quality of Life Questionnaire-Core 30 (QLQC30) and-Oesophageal Cancer Module (QLQ-OES24) questionnaires pretreatment and at 3, 6, 9, and 12 months postoperatively. The nCRT group also received preoperative questionnaires. Physical functioning (PF; QLQ-C30) and eating problems (EA; QLQ-OES24) were chosen as predefined primary end points. Predefined secondary end points were global QOL (GQOL; QLQ-C30), fatigue (FA; QLQ-C30), and emotional problems (EM; QLQ-OES24).

\section{Results}

A total of 363 patients were analyzed. No statistically significant differences in postoperative HRQOL were found between treatment groups. In the nCRT group, PF, EA, GQOL, FA, and EM scores deteriorated 1 week after nCRT (Cohen's d: $-0.93, P<.001 ; 0.47, P<.001 ;-0.84, P<.001$; $1.45, P<.001$; and $0.32, P=.001$, respectively). In both treatment groups, all end points declined 3 months postoperatively compared with baseline (Cohen's $\mathrm{d}$ : $-1.00,0.33,-0.47,-0.34$, and 0.33 , respectively; all $P<.001$ ), followed by a continuous gradual improvement. EA, GQOL, and EM were restored to baseline levels during follow-up, whereas PF and FA remained impaired 1 year postoperatively (Cohen's d: 0.52 and -0.53 , respectively; both $P<.001$ ).

\section{Conclusion}

Although HRQOL declined during $\mathrm{nCRT}$, no effect of $\mathrm{nCRT}$ was apparent on postoperative $\mathrm{HRQOL}$ compared with surgery alone. In addition to the improvement in survival, these findings support the view that $\mathrm{nCRT}$ according to the Chemoradiotherapy for Esophageal Cancer Followed by Surgery Study-regimen can be regarded as a standard of care.

\section{J Clin Oncol 36:268-275. (C) 2017 by American Society of Clinical Oncology}

\section{INTRODUCTION}

Esophageal cancer is characterized by high recurrence rates and poor 5-year survival after primary surgical resection. ${ }^{1}$ To improve the radicality of surgery and long-term survival, many trials on the added value of neoadjuvant therapy have been undertaken. $^{2-8}$

One of the largest and most recent trials is the Chemoradiotherapy for Esophageal Cancer Followed by Surgery Study (CROSS). The randomized CROSS trial compared carboplatin plus paclitaxelbased neoadjuvant concurrent chemoradiotherapy 
(nCRT) regimen plus surgery with surgery alone in patients with esophageal or esophagogastric junctional cancer from eight centers in the Netherlands. Long-term results showed a statistically significant and clinically relevant increase in survival for both squamous cell and adenocarcinoma subtypes, with acceptable toxicity., ${ }^{9,10}$ On the basis of these results, the CROSS regimen is now standard treatment in many countries.

The enhanced emphasis on health-related quality of life (HRQOL) and other patient-reported outcome measures assumes a more prominent role for these factors as end points in clinical cancer trials. ${ }^{11}$ An esophagectomy is a major operation with substantial morbidity and mortality and may have a profound effect on patients' QOL. ${ }^{12-14}$ However, in the field of esophageal cancer, only limited high-quality data on HRQOL are available. So far, HRQOL data have been reported in two randomized esophageal cancer trials, which compared transthoracic versus transhiatal esophagectomy in patients who underwent primary surgery without neoadjuvant therapy and primary surgery versus definitive CRT. ${ }^{15,16}$ Results from randomized trials in patients with esophageal cancer investigating the effect of combined neoadjuvant therapy and surgery on HRQOL have not yet been published. The available evidence comes from two small observational studies. Both studies suggested that the addition of nCRT to surgery had no influence on postoperative HRQOL, but they were likely influenced by selection bias and lacked statistical power. ${ }^{17,18}$

The primary aim of this substudy of the CROSS trial, with HRQOL as a secondary end point, was to compare HRQOL in patients with esophageal or junctional cancer who received nCRT plus surgery or surgery alone. Furthermore, the effect of nCRT on HRQOL before surgery and the effect of surgery on HRQOL were examined over time. It was hypothesized that nCRT impairs HRQOL before surgery but does not affect postoperative recovery in terms of HRQOL.

\section{PATIENTS AND METHODS}

Details of this randomized trial have been reported previously and are summarized in the Appendix Trial Design (online only)., ${ }^{9,10,19}$

\section{HRQOL Measurement}

The self-report questionnaires were mailed after random assignment and 3, 6, 9, and 12 months postoperatively. Postoperative HRQOL was compared between both groups using date of surgery as reference point. Patients who were randomly assigned to the nCRT group also received questionnaires 1 week after nCRT (ie, 3 to 5 weeks before surgery).

Cancer-specific HRQOL was measured with the European Organisation for Research and Treatment of Cancer (EORTC) Quality of Life Questionnaire-Core 30 (QLQ-C30), a validated self-report questionnaire for patients with cancer. ${ }^{20}$ Tumor-specific HRQOL was measured by the EORTC QLQ-Oesophageal Cancer Module (QLQ-OES24), because the currently used derivative QLQ-OES18 was not yet available. ${ }^{21}$

End points were predefined by consensus discussion with experienced upper-GI surgical oncologists, medical oncologists, and nurse practitioners before analysis of the data. End points were selected based on clinical relevance and hypothesized association with nCRT. This led to the primary end points of physical functioning (PF; QLQ-C30) and eating problems (EA; QLQ-OES24). Secondary end points were defined as global QOL (GQOL; QLQ-C30), fatigue (FA; QLQ-C30), and emotional problems (EM; QLQ-OES24).

\section{Statistical Analysis}

Data were analyzed on an intention-to-treat basis, with comparison of HRQOL as primary objective. Pretreatment characteristics were compared using the Mann-Whitney or Student's $t$ test for continuous variables and the $\chi^{2}$ or Fisher's exact test for categorical data.

Questionnaire scores were computed according to EORTC guidelines. ${ }^{22}$ Baseline HRQOL scores were compared using the Student's $t$ test. Differential effects over time between treatment groups and longitudinal comparison of the baseline scores and scores from follow-up measurements $(3,6,9$, and 12 months postoperatively) were performed using mixed modeling. If there were no statistically significant differences over time between both groups, baseline scores and scores from the postoperative measurements of both groups were combined to analyze longitudinal HRQOL. Use of mixed modeling enabled the analysis of all data, because it allowed for inclusion of questionnaire scores from patients with different numbers of completed measurements. ${ }^{23}$ Therefore, the statistical analyses included data from patients who were unable to complete the questionnaires on one or more occasions and from those who dropped out during the trial. Mean differences over time and differential effects over time between treatment groups were described for statistically significant outcomes. Cohen's d (CD) effect sizes were calculated to give an indication of the clinical relevance of effects and to enable standardized comparison between results from different outcome variables. CD effect sizes were derived from the beta estimates in the mixed modeling procedure through standardization of both outcome and predictor variables. CD values of 0.2 , 0.5 , and 0.8 indicate small, medium, and large effects, respectively. ${ }^{24}$ Values $\geq 0.5$ were considered clinically relevant. ${ }^{25}$ In a separate analysis, recurrence of disease and death in the subsequent time period were included as control variables, which enabled the evaluation of possible effect of recurrence of disease and death on the trajectory of HRQOL scores. Recurrence of disease was defined as the earliest occurrence of disease progression resulting in irresectability, locoregional recurrence (after completion of therapy), or distant dissemination (before, during, or after treatment). To correct for multiple testing, statistical significance was set at $P<.01$ (the main analyses included five comparisons, and thus, a Bonferroni correction of .05/5 was applied), except for baseline comparisons. For those latter analyses, $P<.05$ was considered significant. All reported $P$ values are two sided. Statistical analysis was performed using Statistical Package for the Social Sciences software, version 21.0 (SPSS, Chicago, IL).

\section{RESULTS}

Of the 368 randomly assigned patients, 363 were included in the HRQOL analysis. Two withdrew consent, two were enrolled in the trial before the HRQOL study started, and one center (which included one patient) did not participate in the HRQOL study (Fig 1). There were no clinically relevant differences in pretreatment characteristics between groups (Table 1). Because of an administrative error, 89 patients did not receive baseline questionnaires (nCRT group, $\mathrm{n}=58$; surgery-alone group, $\mathrm{n}=31$ ). These patients were not excluded, because their baseline characteristics did not differ significantly from the study population (data not shown), and follow-up questionnaires were correctly completed.

Overall response rates at the different measurement points were $54 \%$ to $76 \%$ and were lower in the surgery-alone group than in the nCRT group (Table 2). At each measurement point, pretreatment characteristics (age, sex, tumor location, cT stage, $\mathrm{cN}$ stage, and WHO performance status) of patients who completed the questionnaires were not statistically different between the two groups (data not shown). In the nCRT group, the median time to 


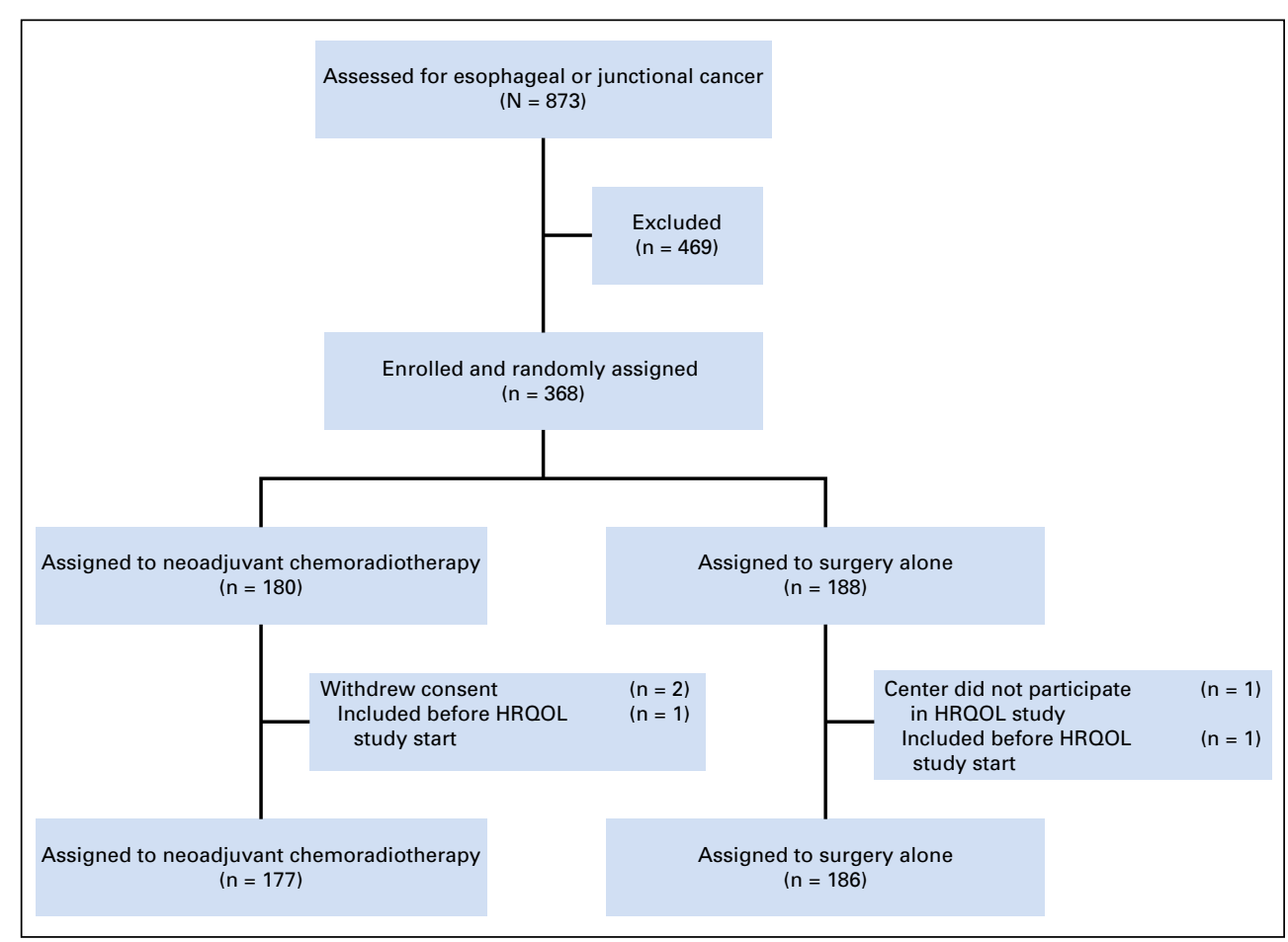

Fig 1. CONSORT diagram. HROOL, healthrelated quality of life.

surgery calculated from the day of last radiation treatment was 46 days (interquartile range, 40 to 55 days). Mean scores of HRQOL domains that were not predefined end points are listed in Table 3 .

\section{Predefined Primary End Points}

$P F$. As shown in Figure 2A, baseline PF levels and all changes over time were comparable between groups $(P=.60$ and $P=.18$, respectively). PF declined at 3 months postoperatively $(-18 ; P<.001$; $\mathrm{CD},-1.00 ; 95 \% \mathrm{CI},-1.14$ to -0.86$)$ and improved from 3 to 6 months postoperatively $(+5 ; P<.001 ; \mathrm{CD}, 0.30 ; 95 \% \mathrm{CI}, 0.18$ to $0.41)$. From then, the improvement was no longer statistically significant ( $9 \vee 6$ months, $P=.07 ; 12 v 9$ months, $P=.27$ ), and baseline levels were not reached during follow-up $(-8 ; P<.001 ; \mathrm{CD},-0.53$; $95 \% \mathrm{CI},-0.67$ to -0.39$)$. In the nCRT group, PF declined 1 week after nCRT $(-17 ; P<.001 ; \mathrm{CD},-0.93 ; 95 \% \mathrm{CI},-1.12$ to -0.74$)$.

$E A$. As shown in Figure 2B, no statistically significant differences in EA were found at baseline $(P=.20)$, and changes over time were comparable between groups $(P=.45)$. Three months postoperatively, EA had worsened in both groups $(+8 ; P<.001$; CD, $0.32 ; 95 \% \mathrm{CI}$, 0.15 to 0.50$)$ and thereafter improved from 3 to 6 months ( -9 ; $P<.001$; CD, $-0.32 ; 95 \% \mathrm{CI},-0.44$ to -0.20$)$ and from 6 to 9 months $(+5 ; P=.001 ; \mathrm{CD},-0.22 ; 95 \% \mathrm{CI},-0.34$ to -0.09$)$. In both groups, 6 months postoperatively, EA levels returned to baseline $(P=.98)$, and no further improvement was found after 12 months of follow-up compared with baseline levels $(P=.01)$. The nCRT group reported a deterioration in EA 1 week after completion of nCRT $(+12 ; P=.001 ; \mathrm{CD}, 0.47 ; 95 \% \mathrm{CI}, 0.21$ to 0.72$)$.

\section{Predefined Secondary End Points}

GQOL. As shown in Figure 2C, baseline GQOL scores and all changes in GQOL over time were comparable between groups
( $P=.53$ and $P=.76$, respectively). GQOL scores significantly declined 3 months postoperatively $(-10 ; P=.002$; CD, $-0.47 ; 95 \%$ $\mathrm{CI},-0.62$ to -0.31 ), improved between 3 and 6 months postoperatively ( $+4 ; P=.001 ; \mathrm{CD}, 0.24 ; 95 \% \mathrm{CI}, 0.10$ to 0.37$)$, reached baseline levels 9 months postoperatively $(P=.31)$, and stabilized subsequently $(P=.34)$. Compared with baseline, patients in the nCRT group reported significantly worse GQOL 1 week after nCRT $(-17 ; P<.001 ; \mathrm{CD},-0.84 ; 95 \% \mathrm{CI},-1.08$ to -0.60$)$.

FA. As shown in Figure 2D, baseline FA levels were comparable between groups $(P=.42)$, and there were no statistically significant differences in changes over time $(P=.30)$. Postoperatively, FA levels worsened $(+24 ; P<.001$; CD, 1.01; 95\% CI, 0.86 to 1.16 ) but subsequently improved in the periods from 3 to 6 months $(-8 ; P<.001$; CD, $-0.34 ; 95 \% \mathrm{CI},-0.46$ to -0.22$)$. Thereafter, FA levels remained stable from 6 to 9 months $(P=.04)$ and from 9 to 12 months $(P=.58)$ but did not return to baseline levels ( $+10 ; P<.001 ; \mathrm{CD}, 0.52 ; 95 \% \mathrm{CI}, 0.38$ to 0.65$)$. In the nCRT group, a significant deterioration was reported 1 week after nCRT (+34; $P<.001 ; \mathrm{CD}, 1.45 ; 95 \% \mathrm{CI}, 1.23$ to 1.66$)$.

$E M$. As shown in Figure 2E, baseline EM scores were comparable between groups $(P=.26)$, and both groups reported comparable changes over time $(P=.75)$. Three months postoperatively, EM worsened $(+8 ; P<.001 ; \mathrm{CD}, 0.33$; $95 \% \mathrm{CI}, 0.18$ to $0.49)$ but improved from 3 to 6 months $(-6 ; P<.001 ; \mathrm{CD},-0.26$; $95 \% \mathrm{CI},-0.40$ to -0.13$)$ and from 6 to 9 months $(-5 ; P=.003$; $\mathrm{CD},-0.22 ; 95 \% \mathrm{CI},-0.36$ to -0.08$)$ postoperatively and stabilized thereafter ( 9 to 12 months, $P=.74$ ). Baseline levels were reached at 6 months $(P=.39)$ and stabilized thereafter $(P=.05)$. Patients in the nCRT group reported a deterioration in EM 1 week after nCRT ( $+9 ; P=.001$; CD, $0.32 ; 95 \% \mathrm{CI}, 0.14$ to 0.50$)$.

Results of the model including randomized grouping for longitudinal effects are shown in Appendix Tables A1 to A5 (online only). 


\begin{tabular}{|c|c|c|}
\hline \multirow[b]{2}{*}{ Characteristic } & \multicolumn{2}{|c|}{ No. (\%) } \\
\hline & $\begin{array}{l}\text { nCRT Plus Surgery } \\
\qquad(\mathrm{n}=177)\end{array}$ & $\begin{array}{c}\text { Surgery Alone } \\
\quad(\mathrm{n}=186)\end{array}$ \\
\hline \multicolumn{3}{|l|}{ Age, years } \\
\hline Median & 60 & \\
\hline IOR & $55-67$ & $54-66$ \\
\hline Male sex & $134(76)$ & $151(81)$ \\
\hline \multicolumn{3}{|l|}{ Tumor type } \\
\hline Adenocarcinoma & $134(76)$ & $140(75)$ \\
\hline Squamous cell carcinoma & $40(23)$ & $42(23)$ \\
\hline Large-cell undifferentiated & $3(2)$ & $4(2)$ \\
\hline \multicolumn{3}{|l|}{ Tumor location* } \\
\hline \multicolumn{3}{|l|}{ Esophagus } \\
\hline Proximal third & $4(2)$ & $4(2)$ \\
\hline Middle third & $24(14)$ & $23(12)$ \\
\hline Distal third & $104(59)$ & $107(58)$ \\
\hline Esophagogastric junction & $39(22)$ & $48(26)$ \\
\hline Missing data & $6(3)$ & $4(2)$ \\
\hline \multicolumn{3}{|l|}{ Clinical T stage $\dagger$} \\
\hline cT1 & $1(1)$ & $1(1)$ \\
\hline cT2 & $26(15)$ & $35(19)$ \\
\hline сT3 & 149 (84) & $145(78)$ \\
\hline cT4 $\ddagger$ & 0 & $1(1)$ \\
\hline Could not be determined§ & $1(1)$ & $4(2)$ \\
\hline \multicolumn{3}{|l|}{ Clinical N stage\| } \\
\hline No & $59(33)$ & $58(31)$ \\
\hline N1 & $115(65)$ & $118(63)$ \\
\hline Could not be determined§ & $3(2)$ & $10(5)$ \\
\hline \multicolumn{3}{|l|}{ WHO performance status } \\
\hline 0 & $144(81)$ & $161(87)$ \\
\hline 1 & $33(19)$ & $25(13)$ \\
\hline \multicolumn{3}{|c|}{ 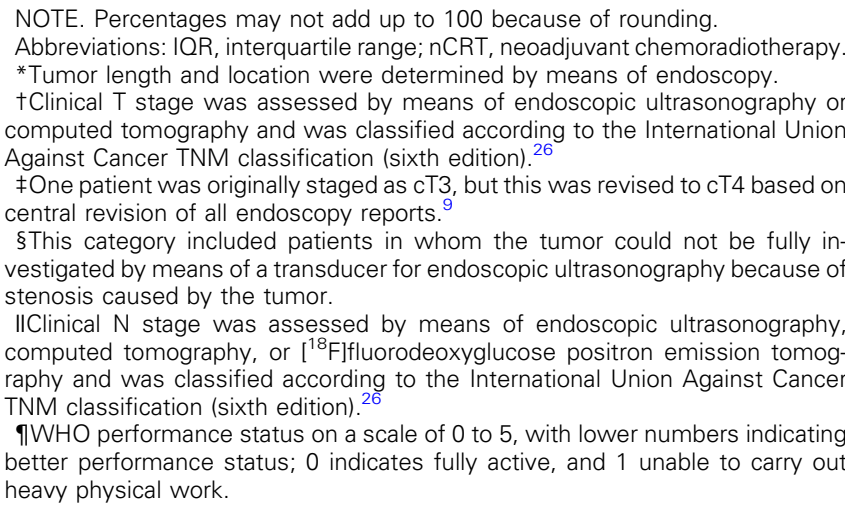 } \\
\hline
\end{tabular}

\section{Influence of Recurrence of Disease and Death}

Inclusion of recurrence of disease and death as control variables did not influence the overall trends in HRQOL trajectories (data not shown). However, the deterioration and restoration of primary and secondary end points during follow-up were worse for patients who developed recurrent disease and for patients who died in the subsequent time period (data not shown). Patients in the surgery-alone group who died during follow-up showed the most severe deteriorations, especially in the 6- and 9-month follow-up measures.

\section{Influence of Missing Baseline Questionnaires}

Availability of a completed baseline questionnaire was included as control variable. Inclusion of this variable did not influence the described overall trends in HRQOL trajectories (data not shown).

\section{DISCUSSION}

This randomized trial did not show statistically significant differences in postoperative HRQOL in patients with esophageal or junctional cancer treated with a multimodality regimen based on carboplatin plus paclitaxel with 41.4 Gy of concurrent radiotherapy plus surgery, compared with patients who underwent surgery alone. Patients in the nCRT group experienced deterioration in all HRQOL end points immediately after completion of nCRT, but this did not affect recovery during the first postoperative year in terms of HRQOL.

In both treatment groups, all primary and secondary HRQOL end points declined postoperatively, but most were restored to pretreatment levels within 1 year postoperatively. GQOL, EA, and EM reached baseline levels 6 months (GQOL and EA) and 9 months postoperatively (EM) and stabilized from then. However, $\mathrm{PF}$ and FA levels were not restored to pretreatment levels during the first year of follow-up, and corresponding effect sizes were clinically relevant (CD, -0.53 and 0.52 , respectively). The scores of these domains stabilized 6 and 9 months postoperatively, which suggests that further spontaneous improvement to be unlikely.

This study is the first clinical trial and the largest available analysis to our knowledge comparing HRQOL in patients with esophageal cancer who underwent neoadjuvant therapy plus surgery or surgery alone. Two small observational studies have suggested that postoperative HRQOL is not affected by addition of nCRT to surgery, but these studies used different nCRT regimens and were criticized because of the potential influence of selection bias and lack of statistical power. ${ }^{17,18}$ The randomized design of our study largely excludes selection bias, and the relatively large sample size increases the power to detect small but clinically relevant differences. Hence, these results demonstrate more reliably that postoperative HRQOL is not affected by nCRT, thereby confirming the results from these previous studies. These findings can help clinicians and patients to make more properly informed treatment decisions, especially patients who fear the negative effect of neoadjuvant treatment. Besides the relatively low toxicity and the strong effect on survival after nCRT plus surgery according to CROSS, ${ }^{9,10}$ the comparable effect on postoperative HRQOL with surgery alone confirms that the benefits of this effective regimen outweigh its harms. Nevertheless, it should be noted that the application of nCRT delays surgery and subsequent postoperative recovery by 2 to 3 months. This delay is substantial, especially for patients who turn out to be nonsurvivors. Furthermore, the long-term effects of adding nCRT to surgery on HRQOL are largely unknown and need to be further explored. Although it has been shown that nCRT containing cisplatin and fluorouracil with 66 Gy of concurrent radiotherapy significantly hampers long-term HRQOL, the CROSS regimen theoretically may have fewer negative effects because of the mild toxicity of the applied chemotherapeutic agents and the relatively low radiation dose. ${ }^{27}$

In line with our study, a profound deterioration in HRQOL scores immediately after completion of nCRT has been described in the phase II CROSS-I trial and other observational studies. ${ }^{17,18,28}$ 


\begin{tabular}{|c|c|c|c|c|c|c|}
\hline \multirow[b]{3}{*}{ Status } & \multicolumn{6}{|c|}{ Measurement Point } \\
\hline & \multirow[b]{2}{*}{ Baseline } & \multirow[b]{2}{*}{ Post-nCRT } & \multicolumn{4}{|c|}{ Postsurgery (months) } \\
\hline & & & 3 & 6 & 9 & 12 \\
\hline Eligible & 363 & 177 & 342 & 308 & 285 & 260 \\
\hline nCRT + surgery & 177 & 177 & 163 & 151 & 145 & 136 \\
\hline Surgery alone & 186 & & 179 & 157 & 140 & 124 \\
\hline Returned total ( $\%$ of eligible) & $235(65)$ & $104(59)$ & $228(67)$ & $210(68)$ & $185(65)$ & $166(64)$ \\
\hline nCRT + surgery & $134(76)$ & $104(59)$ & $119(73)$ & $113(75)$ & $103(71)$ & $94(69)$ \\
\hline Surgery alone & $101(54)$ & NA & 109 (61) & $97(62)$ & $82(59)$ & $72(58)$ \\
\hline Died & 0 & 0 & 21 & 55 & 78 & 103 \\
\hline Too ill & 0 & 24 & 38 & 27 & 36 & 32 \\
\hline Randomly missing/other & $128^{*}$ & 49 & 76 & 71 & 64 & 62 \\
\hline
\end{tabular}

This decline in all end points 1 week after completion of nCRT is explained by persisting adverse effects of chemotherapy and radiotherapy, such as anorexia, FA, esophagitis, and hematologic toxicity. This emphasizes the need for sufficient time between nCRT and surgery, which allows patients to recover and reach more optimal physical condition before surgery. Earlier studies have suggested that postponement of surgery to at least 12 weeks after nCRT does not jeopardize long-term oncologic outcome and even tends to increase the pathologic complete response rate, which might improve prognostication. ${ }^{29,30}$ Unfortunately, no HRQOL

\begin{tabular}{|c|c|c|c|c|c|c|c|c|c|c|c|c|}
\hline \multirow[b]{4}{*}{ Measure } & \multicolumn{12}{|c|}{$\begin{array}{c}\text { Measurement Point } \\
\text { Mean (SD) }\end{array}$} \\
\hline & \multirow{2}{*}{\multicolumn{2}{|c|}{ Baseline }} & \multirow{2}{*}{\multicolumn{2}{|c|}{ Post-nCRT }} & \multicolumn{8}{|c|}{ Postsurgery (months) } \\
\hline & & & & & \multicolumn{2}{|c|}{3} & \multicolumn{2}{|c|}{6} & \multicolumn{2}{|c|}{9} & \multicolumn{2}{|c|}{12} \\
\hline & $\begin{array}{l}\text { Surgery } \\
\text { Alone }\end{array}$ & $\mathrm{nCRT}$ & $\begin{array}{l}\text { Surgery } \\
\text { Alone }\end{array}$ & nCRT & $\begin{array}{l}\text { Surgery } \\
\text { Alone }\end{array}$ & $\mathrm{nCRT}$ & $\begin{array}{l}\text { Surgery } \\
\text { Alone }\end{array}$ & $\mathrm{nCRT}$ & $\begin{array}{l}\text { Surgery } \\
\text { Alone }\end{array}$ & $\mathrm{nCRT}$ & $\begin{array}{l}\text { Surgery } \\
\text { Alone }\end{array}$ & nCRT \\
\hline \multicolumn{13}{|l|}{ QLQ-C30 } \\
\hline \multicolumn{13}{|l|}{ Functional scales } \\
\hline Role & $85(22)$ & $88(24)$ & NA & $57(29)$ & 55 (32) & $60(30)$ & $68(29)$ & $68(30)$ & $73(26)$ & $76(28)$ & $78(24)$ & $77(27)$ \\
\hline Emotional & $71(20)$ & $71(21)$ & NA & $74(21)$ & $75(24)$ & $78(21)$ & $76(22)$ & $80(23)$ & $80(18)$ & $82(19)$ & $77(20)$ & $83(20)$ \\
\hline Cognitive & $89(16)$ & $93(15)$ & NA & $84(21)$ & $82(21)$ & $82(22)$ & $85(18)$ & $85(17)$ & $84(18)$ & $86(17)$ & $84(19)$ & $87(19)$ \\
\hline Social & $85(20)$ & $87(20)$ & NA & 77 (24) & $68(27)$ & $69(28)$ & 75 (25) & $80(21)$ & $78(25)$ & $84(22)$ & $83(23)$ & $85(23)$ \\
\hline \multicolumn{13}{|l|}{ Symptom scores } \\
\hline Nausea and vomiting & $12(20)$ & $8(14)$ & NA & $22(28)$ & $21(24)$ & $19(23)$ & $13(20)$ & $21(24)$ & $12(18)$ & $13(18)$ & $11(16)$ & $12(19)$ \\
\hline Pain & $14(20)$ & $14(20)$ & NA & $31(29)$ & $23(28)$ & $17(23)$ & $21(25)$ & $17(24)$ & $15(24)$ & $13(22)$ & $17(20)$ & $11(19)$ \\
\hline Dyspnea & $10(20)$ & $5(12)$ & NA & $20(26)$ & $26(27)$ & $28(29)$ & $22(27)$ & $24(26)$ & $22(26)$ & $18(23)$ & $16(22)$ & $17(24)$ \\
\hline Insomnia & $20(28)$ & $23(26)$ & NA & $29(31)$ & $26(31)$ & $22(30)$ & $22(26)$ & $20(28)$ & $26(30)$ & $15(23)$ & $19(26)$ & $17(26)$ \\
\hline Loss of appetite & $14(24)$ & $13(25)$ & NA & $41(36)$ & 30 (33) & 34 (33) & $18(27)$ & $24(33)$ & $13(25)$ & $12(20)$ & $13(22)$ & $14(24)$ \\
\hline Constipation & $6(15)$ & $8(19)$ & NA & $24(33)$ & $13(26)$ & $9(23)$ & $10(19)$ & $6(17)$ & $9(20)$ & $6(16)$ & $10(22)$ & $9(20)$ \\
\hline Diarrhea & $5(12)$ & $2(10)$ & NA & $14(26)$ & $21(27)$ & $21(28)$ & $22(26)$ & $20(25)$ & $16(22)$ & $17(23)$ & $17(21)$ & $15(23)$ \\
\hline Financial worries & $6(17)$ & $9(20)$ & NA & $8(19)$ & $10(20)$ & $12(24)$ & $14(24)$ & $13(21)$ & $9(18)$ & $13(20)$ & $13(24)$ & $12(22)$ \\
\hline \multicolumn{13}{|l|}{ QLQ-OES24 } \\
\hline Dysphagia & $62(34)$ & 64 (35) & NA & $53(32)$ & 70 (31) & $74(28)$ & $79(29)$ & $75(30)$ & $75(33)$ & $76(30)$ & 74 (34) & $77(29)$ \\
\hline Deglutition & $16(23)$ & $15(24)$ & NA & $14(20)$ & $19(23)$ & $21(23)$ & $15(24)$ & $13(21)$ & $18(26)$ & $15(21)$ & $13(20)$ & $15(23)$ \\
\hline Swallowing of saliva & $17(30)$ & $18(31)$ & NA & $18(29)$ & $18(31)$ & $18(30)$ & $15(29)$ & $11(26)$ & $17(30)$ & $16(29)$ & $12(22)$ & $15(27)$ \\
\hline Aspiration & $13(23)$ & $13(24)$ & NA & $9(19)$ & $19(25)$ & $23(26)$ & $16(25)$ & $15(23)$ & $17(25)$ & $15(21)$ & $14(23)$ & $16(23)$ \\
\hline Gl symptoms (24) & $22(19)$ & $15(15)$ & NA & $21(19)$ & $23(21)$ & $18(18)$ & $22(19)$ & $20(18)$ & $21(21)$ & $21(20)$ & $24(23)$ & $20(21)$ \\
\hline Gl symptoms (18) & $9(19)$ & $7(16)$ & NA & $16(23)$ & $17(26)$ & $12(20)$ & $18(23)$ & $17(22)$ & $18(24)$ & $20(24)$ & $21(25)$ & $18(24)$ \\
\hline Pain & $23(24)$ & $18(21)$ & NA & $32(25)$ & $12(16)$ & $12(19)$ & $12(18)$ & $11(13)$ & $11(17)$ & $11(19)$ & $12(19)$ & $8(13)$ \\
\hline Dry mouth & $14(24)$ & $9(20)$ & NA & $25(31)$ & $19(29)$ & $21(30)$ & $13(24)$ & $21(26)$ & $16(25)$ & $20(31)$ & $18(24)$ & $16(24)$ \\
\hline Trouble with taste & $10(23)$ & $7(21)$ & NA & 37 (37) & $24(33)$ & $24(33)$ & $13(26)$ & $14(25)$ & $13(24)$ & $11(24)$ & $13(23)$ & $9(21)$ \\
\hline Trouble with coughing & $16(22)$ & $13(21)$ & NA & $31(31)$ & 37 (34) & $41(35)$ & $29(29)$ & $25(30)$ & $29(29)$ & $24(27)$ & $22(24)$ & $16(20)$ \\
\hline Trouble with speaking & $6(17)$ & $4(16)$ & NA & $6(17)$ & $19(28)$ & $18(29)$ & $11(25)$ & $11(25)$ & $13(28)$ & $11(25)$ & $14(28)$ & $11(25)$ \\
\hline Hair loss & $0(0)$ & $0(0)$ & NA & $24(29)$ & $8(24)$ & $23(34)$ & $24(25)$ & $18(30)$ & $29(37)$ & $26(40)$ & $19(26)$ & $15(29)$ \\
\hline
\end{tabular}




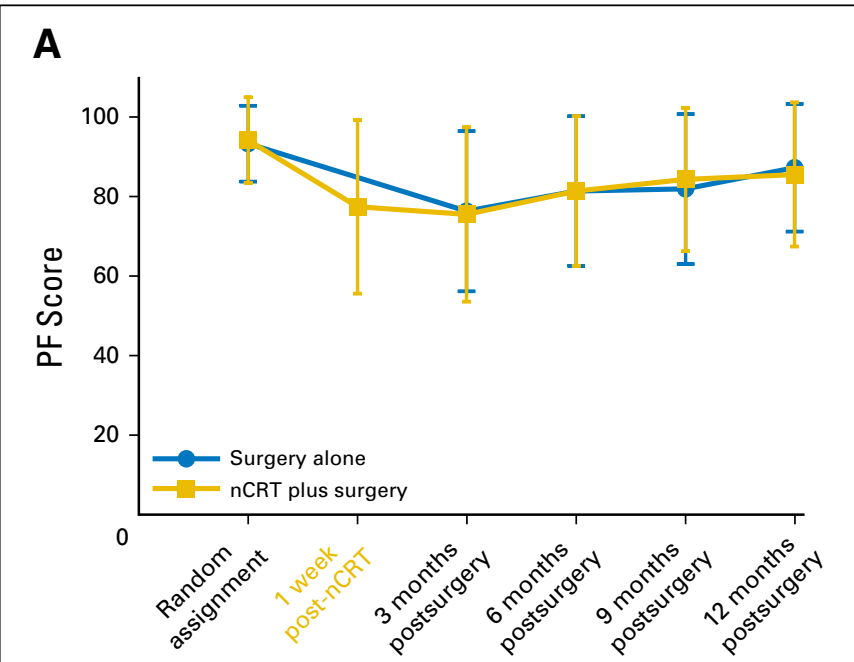

Measurement Point

C

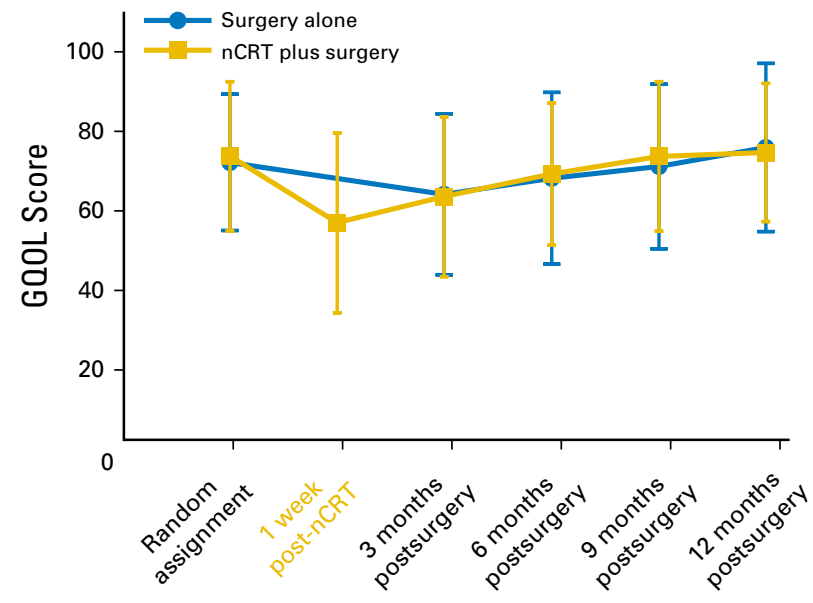

Measurement Point

E

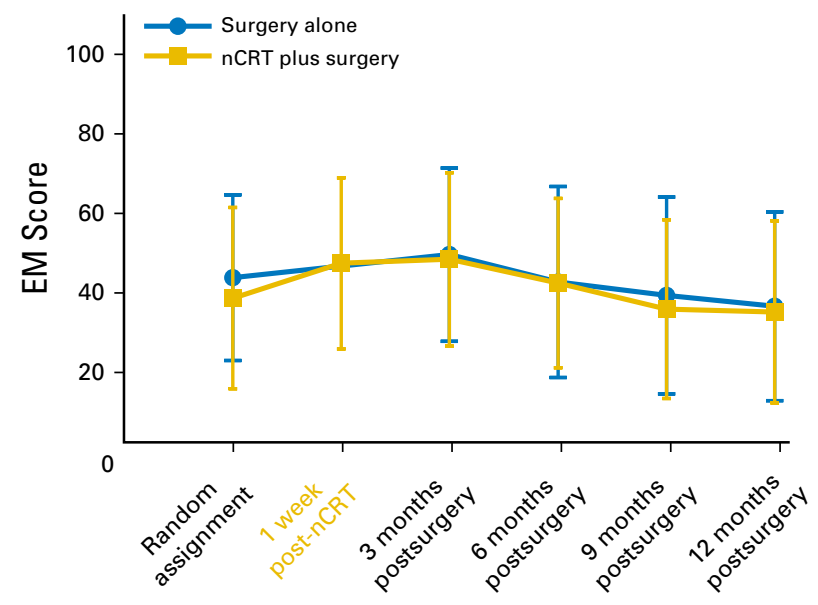

B

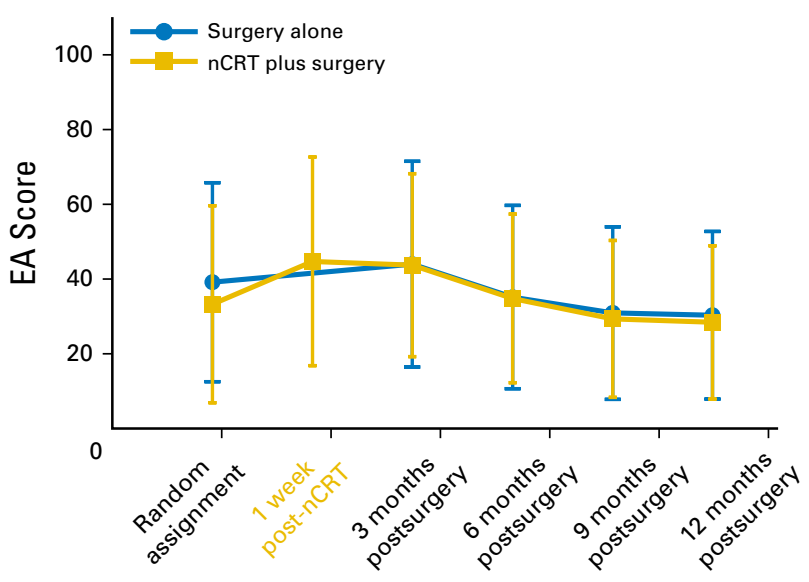

Measurement Point

D

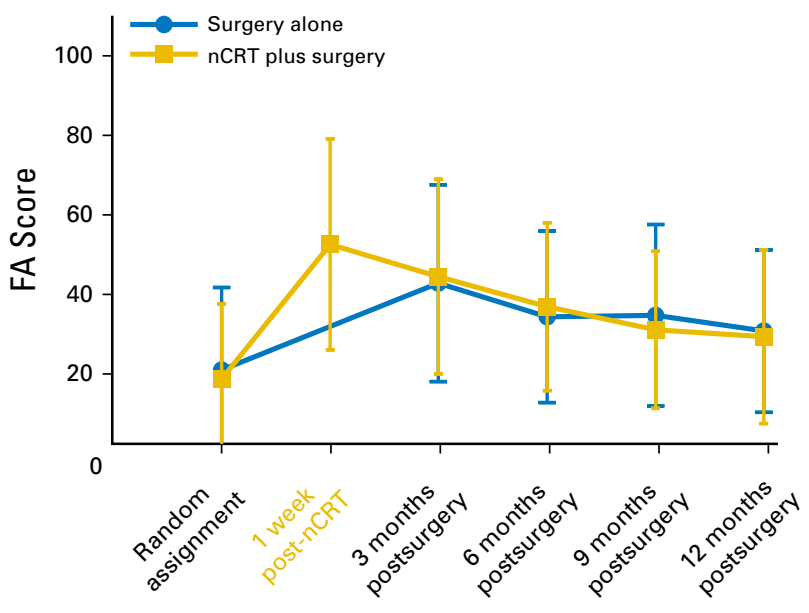

Measurement Point

\section{Measurement Point}

Fig 2. Mean scores with standard deviations for primary end points (A) physical functioning (PF) and (B) eating problems (EA) and secondary end points (C) global quality of life (GQOL), (D) fatigue (FA), and (E) emotional problems (EM) according to treatment group. nCRT, neoadjuvant chemoradiotherapy. 
assessment was performed during nCRT or just before surgery. In clinical practice, we have witnessed general improvements in patients' condition in the period between nCRT and surgery. Therefore, we recommend timing of surgery to be guided by patients' condition, and we advocate that surgery should be postponed to up to 12 weeks after completion of nCRT in case of persisting adverse events or bad general condition. To further optimize the timing of surgery, the course of HRQOL in the period between nCRT and surgery should be monitored more carefully. On the basis of the available literature and our clinical experience, it seems that HRQOL substantially improves over a period of 6 to 12 weeks. ${ }^{17}$

Although some studies have suggested that the effect of esophagectomy on HRQOL is restored within 1 year postoperatively ${ }^{15}$ or can be attributed to only a small group of patients, ${ }^{31}$ most studies have shown lasting and substantial negative effects. ${ }^{13,14,32}$ This is confirmed by the results of our study, in which two of the five end points (ie, PF and FA) did not return to baseline levels during the first year follow-up, and none of the end points improved compared with baseline levels (for patients suffering from esophageal cancer). These effects could only partly be explained by recurrence of disease or death in the subsequent study period, emphasizing the adverse effect of esophagectomy on HRQOL. Cognitive behavioral therapy, which was not routinely offered in our study, might be successful in treating patients with lasting FA. ${ }^{33}$ Furthermore, new treatment strategies, such as minimally invasive esophagectomy and an active surveillance approach after nCRT (instead of standard surgery), might improve HRQOL in these patients. $^{34,35}$

Limitations of this study include overall attrition and lower response rates in the surgery-alone group than in the nCRT group. Attrition is inevitable in HRQOL studies with severely ill patients. Nevertheless, at each measurement point, pretreatment prognostic parameters of patients who completed the questionnaires were comparable between the two treatment groups, suggesting the effect of attrition bias to be small. Lower response rates in the surgery-alone group might be explained by primary surgery being standard treatment during the performance of the trial. Consequently, patients in the surgery-alone group could have been less motivated to complete HRQOL questionnaires than patients in the experimental nCRT group. Another possible explanation is the increasing rate of recurrence being more common in the surgeryalone group.

Because of the relatively low number of older patients (patients age $\geq 76$ years were excluded from the trial) and patients with poorer performance status (patients with $\mathrm{WHO}>2$ were also excluded), results from this study cannot be generalized to these specific categories of vulnerable patients. The effect of this treatment regimen on HRQOL will need to be tested for these subgroups of patients in future studies.

Furthermore, it has been pointed out previously that patients who receive neoadjuvant treatment may report better recovery from surgery, as a result of adjustments to toxicity as experienced during neoadjuvant treatment leading to a re-evaluation of internal standards (ie, response shift). In our study, it was not possible to correct for this potential effect. ${ }^{17}$

Finally, although formally validated, sensitivity of HRQOL questionnaires remains uncertain, and these questionnaires might be too crude to detect small but clinically relevant differences. To optimize precision, both generic and disease-specific questionnaires were used, and together with the large sample size of the current trial, we expect sensitivity to be relatively high compared with that of earlier studies on this topic. Of note, the QLQ-OES24 questionnaire has been refined into the QLQ-OES18, with revision of the hypothesized scales and the removal of two single items. We do not believe this invalidates the results of our study, because the EA scale was retained in its original form. The EM scale showed modest to high correlations within all validation analyses but was deleted because of overlap with the QLQ-C30 questionnaire. ${ }^{21}$

In conclusion, although HRQOL declined immediately after nCRT, no effect of nCRT according to CROSS was apparent on postoperative short-term HRQOL compared with surgery alone. In addition to the earlier described improvement in long-term overall and disease-free survival, these results support the view that nCRT according to this effective regimen should be regarded as a standard of care for patients with locally advanced resectable esophageal or esophagogastric junctional cancer.

\section{AUTHORS' DISCLOSURES OF POTENTIAL CONFLICTS OF INTEREST}

Disclosures provided by the authors are available with this article at jco.org.

\section{AUTHOR CONTRIBUTIONS}

Conception and design: Bo Jan Noordman, Sjoerd M. Lagarde, Maarten C.C.M. Hulshof, Mark I. van Berge Henegouwen, Bas P.L. Wijnhoven, Hanneke W.M. van Laarhoven, Grard A.P. Nieuwenhuijzen, Johannes J. Bonenkamp, Miguel A. Cuesta, Reinoud J.B. Blaisse, Olivier R. Busch, Fiebo J.W. ten Kate, Geert-Jan M. Creemers, Cornelis J.A. Punt, John Th.M. Plukker, Ernst J. Spillenaar Bilgen, Maurice J.C. van der Sangen, Tom Rozema, Katharina Biermann, Jannet C. Beukema,

Caroline M. van Rij, Janny G. Reinders, Hugo W. Tilanus, Ewout W. Steyerberg, Ate van der Gaast, J. Jan B. van Lanschot

Collection and assembly of data: Bo Jan Noordman, Maarten C.C.M. Hulshof, Pieter van Hagen, Mark I. van Berge Henegouwen, Bas P.L. Wijnhoven, Hanneke W.M. van Laarhoven, Grard A.P. Nieuwenhuijzen, Geke A.P. Hospers, Johannes J. Bonenkamp, Miguel A. Cuesta,

Reinoud J.B. Blaisse, Olivier R. Busch, Fiebo J.W. ten Kate, Geert-Jan M. Creemers, Cornelis J.A. Punt, John Th.M. Plukker, Henk M.W. Verheul, Ernst J. Spillenaar Bilgen, Herman van Dekken, Maurice J.C. van der Sangen, Tom Rozema, Katharina Biermann, Jannet C. Beukema, Anna H.M. Piet, Caroline M. van Rij, Janny G. Reinders, Hugo W. Tilanus, Ate van der Gaast, J. Jan B. van Lanschot

Data analysis and interpretation: Bo Jan Noordman, Mathilde G.E.

Verdam, Sjoerd M. Lagarde, Maarten C.C.M. Hulshof, Pieter van Hagen, Mark I. van Berge Henegouwen, Bas P.L. Wijnhoven, Hanneke W.M. van Laarhoven, Grard A.P. Nieuwenhuijzen, Geke A.P. Hospers, Johannes J. Bonenkamp, Miguel A. Cuesta, Reinoud J.B. Blaisse, Olivier R. Busch, Fiebo J.W. ten Kate, Geert-Jan M. Creemers, Cornelis J.A. Punt, John Th.M. Plukker, Ernst J. Spillenaar Bilgen, Maurice J.C. van der Sangen, Tom Rozema, Katharina Biermann, Jannet C. Beukema, Anna H.M. Piet, Caroline M. van Rij, Janny G. Reinders, Ewout W. Steyerberg, Ate van der Gaast, Mirjam A.G. Sprangers, J. Jan B. van Lanschot

Manuscript writing: All authors

Final approval of manuscript: All authors

Accountable for all aspects of the work: All authors 


\section{REFERENCES}

1. Hulscher JB, van Sandick JW, de Boer AG, et al: Extended transthoracic resection compared with limited transhiatal resection for adenocarcinoma of the esophagus. N Engl J Med 347:1662-1669, 2002

2. Kelsen DP, Ginsberg R, Pajak TF, et al: Chemotherapy followed by surgery compared with surgery alone for localized esophageal cancer. N Engl J Med 339:1979-1984, 1998

3. Allum WH, Stenning SP, Bancewicz J, et al: Long-term results of a randomized trial of surgery with or without preoperative chemotherapy in esophageal cancer. J Clin Oncol 27:5062-5067, 2009

4. Cunningham $D$, Allum WH, Stenning SP, et al: Perioperative chemotherapy versus surgery alone for resectable gastroesophageal cancer. N Engl J Med 355:11-20, 2006

5. Ychou M, Boige V, Pignon JP, et al: Perioperative chemotherapy compared with surgery alone for resectable gastroesophageal adenocarcinoma: An FNCLCC and FFCD multicenter phase III trial. J Clin Oncol 29:1715-1721, 2011

6. Walsh TN, Noonan N, Hollywood D, et al: A comparison of multimodal therapy and surgery for esophageal adenocarcinoma. N Engl J Med 335: 462-467, 1996

7. Mariette C, Dahan L, Mornex F, et al: Surgery alone versus chemoradiotherapy followed by surgery for stage I and II esophageal cancer: Final analysis of randomized controlled phase III trial FFCD 9901. J Clin Oncol 32:2416-2422, 2014

8. Sjoquist $\mathrm{KM}$, Burmeister $\mathrm{BH}$, Smithers BM, et al: Survival after neoadjuvant chemotherapy or chemoradiotherapy for resectable oesophageal carcinoma: An updated meta-analysis. Lancet Oncol 12: 681-692, 2011

9. van Hagen $\mathrm{P}$, Hulshof $\mathrm{MC}$, van Lanschot JJ, et al: Preoperative chemoradiotherapy for esophageal or junctional cancer. N Engl J Med 366:2074-2084, 2012

10. Shapiro J, van Lanschot JJB, Hulshof MCCM, et al: Neoadjuvant chemoradiotherapy plus surgery versus surgery alone for oesophageal or junctional cancer (CROSS): Long-term results of a randomised controlled trial. Lancet Oncol 16:1090-1098, 2015

11. Vodicka E, Kim K, Devine EB, et al: Inclusion of patient-reported outcome measures in registered clinical trials: Evidence from ClinicalTrials.gov (20072013). Contemp Clin Trials 43:1-9, 2015
12. De Boer AG, Genovesi PI, Sprangers MA, et al: Quality of life in long-term survivors after curative transhiatal oesophagectomy for oesophageal carcinoma. Br J Surg 87:1716-1721, 2000

13. Djärv T, Lagergren J, Blazeby JM, et al: Longterm health-related quality of life following surgery for oesophageal cancer. Br J Surg 95:1121-1126, 2008

14. Scarpa $M$, Valente $S$, Alfieri $R$, et al: Systematic review of health-related quality of life after esophagectomy for esophageal cancer. World J Gastroenterol 17:4660-4674, 2011

15. de Boer AG, van Lanschot JJ, van Sandick JW, et al: Quality of life after transhiatal compared with extended transthoracic resection for adenocarcinoma of the esophagus. J Clin Oncol 22:4202-4208, 2004

16. Teoh AY, Yan Chiu PW, Wong TC, et al: Functional performance and quality of life in patients with squamous esophageal carcinoma receiving surgery or chemoradiation: results from a randomized trial. Ann Surg 253:1-5, 2011

17. Blazeby JM, Sanford E, Falk SJ, et al: Healthrelated quality of life during neoadjuvant treatment and surgery for localized esophageal carcinoma. Cancer 103:1791-1799, 2005

18. Reynolds JV, McLaughlin R, Moore J, et al: Prospective evaluation of quality of life in patients with localized oesophageal cancer treated by multimodality therapy or surgery alone. Br J Surg 93:1084-1090, 2006

19. van Heijl M, van Lanschot JJ, Koppert LB, et al: Neoadjuvant chemoradiation followed by surgery versus surgery alone for patients with adenocarcinoma or squamous cell carcinoma of the esophagus (CROSS). BMC Surg 8:21, 2008

20. Aaronson NK, Ahmedzai S, Bergman B, et al: The European Organization for Research and Treatment of Cancer QLQ-C30: A quality-of-life instrument for use in international clinical trials in oncology. J Natl Cancer Inst 85:365-376, 1993

21. Blazeby JM, Conroy T, Hammerlid E, et al: Clinical and psychometric validation of an EORTC questionnaire module, the EORTC QLQ-OES18, to assess quality of life in patients with oesophageal cancer. Eur J Cancer 39:1384-1394, 2003

22. Fayers PM, Aaronson NK, Bjordal K, et al: The EORTC QLQ-C30 Scoring Manual (ed 3). Brussels, Belgium, European Organisation for Research and Treatment of Cancer, 2001

23. Twisk J, de Vente W: Attrition in longitudinal studies: How to deal with missing data. J Clin Epidemiol 55:329-337, 2002
24. Cohen J: Statistical Power Analysis for the Behavorial Sciences (ed 2). Hillsdale, NJ, Erlbaum, 1988

25. Norman GR, Sloan JA, Wyrwich KW: Interpretation of changes in health-related quality of life: The remarkable universality of half a standard deviation. Med Care 41:582-592, 2003

26. Sobin LH, Wittekind C (eds): TNM Classification of Malignant Tumors (ed 6). New York, NY, Wiley-Liss, 2002

27. Hurmuzlu M, Aarstad HJ, Aarstad AK, et al: Health-related quality of life in long-term survivors after high-dose chemoradiotherapy followed by surgery in esophageal cancer. Dis Esophagus 24:39-47, 2011

28. van Meerten E, van der Gaast A, Looman CW, et al: Quality of life during neoadjuvant treatment and after surgery for resectable esophageal carcinoma. Int J Radiat Oncol Biol Phys 71:160-166, 2008

29. Shapiro J, van Hagen $P$, Lingsma HF, et al: Prolonged time to surgery after neoadjuvant chemoradiotherapy increases histopathological response without affecting survival in patients with esophageal or junctional cancer. Ann Surg 260:807-813, discussion 813-814, 2014

30. Ruol A, Rizzetto C, Castoro C, et al: Interval between neoadjuvant chemoradiotherapy and surgery for squamous cell carcinoma of the thoracic esophagus: Does delayed surgery have an impact on outcome? Ann Surg 252:788-796, 2010

31. Derogar $M$, Lagergren $P$ : Health-related quality of life among 5-year survivors of esophageal cancer surgery: a prospective population-based study. J Clin Oncol 30:413-418, 2012

32. Lagergren $P$, Avery KN, Hughes $R$, et al: Healthrelated quality of life among patients cured by surgery for esophageal cancer. Cancer 110:686-693, 2007

33. Gielissen MF, Verhagen S, Witjes F, et al: Effects of cognitive behavior therapy in severely fatigued disease-free cancer patients compared with patients waiting for cognitive behavior therapy: A randomized controlled trial. J Clin Oncol 24:4882-4887, 2006

34. Biere SS, van Berge Henegouwen MI, Maas $\mathrm{KW}$, et al: Minimally invasive versus open oesophagectomy for patients with oesophageal cancer: A multicentre, open-label, randomised controlled trial. Lancet 379:1887-1892, 2012

35. Taketa T, Xiao L, Sudo K, et al: Propensitybased matching between esophagogastric cancer patients who had surgery and who declined surgery after preoperative chemoradiation. Oncology 85 : 95-99, 2013

\section{Affiliations}

Bo Jan Noordman, Sjoerd M. Lagarde, Pieter van Hagen, Bas P.L. Wijnhoven, Fiebo J.W. ten Kate, Katharina Biermann, Caroline M. van Rij, Hugo W. Tilanus, Ewout W. Steyerberg, Ate van der Gaast, and J. Jan B. van Lanschot, Erasmus MC-University Medical Center Rotterdam; Mathilde G.E. Verdam, Maarten C.C.M. Hulshof, Mark I. van Berge Henegouwen, Hanneke W.M. van Laarhoven, Olivier R. Busch, Fiebo J.W. ten Kate, Cornelis J.A. Punt, and Mirjam A.G. Sprangers, Academic Medical Center; Miguel A. Cuesta, Henk M.W. Verheul, and Anna H.M. Piet, Vrije Universiteit Medical Center; Herman van Dekken, St Lucas Andreas Hospital, Amsterdam; Grard A.P. Nieuwenhuijzen, Geert-Jan M. Creemers, and Maurice J.C. van der Sangen, Catharina Hospital, Eindhoven; Geke A.P. Hospers, John Th.M. Plukker, and Jannet C. Beukema, University Medical Center Groningen, Groningen; Johannes J. Bonenkamp, Cornelis J.A. Punt, and Tom Rozema, Radboud University Nijmegen Medical Center, Nijmegen; Reinoud J.B. Blaisse and Ernst J. Spillenaar Bilgen, Rijnstate Hospital; Janny G. Reinders, Arnhem Radiotherapeutic Institute, Arnhem; and Tom Rozema, Verbeeten Institute, Tilburg, the Netherlands.

\section{Support \\ Supported by the Dutch Cancer Foundation (KWF Kankerbestrijding).}

Prior Presentation

Presented at the International Society for Diseases of the Esophagus World Congress, Singapore, Singapore, September 19-21, 2016. 
Effect of Neoadjuvant Chemoradiotherapy on Health-Related Quality of Life in Esophageal or Junctional Cancer: Results From the Randomized CROSS Trial

The following represents disclosure information provided by authors of this manuscript. All relationships are considered compensated. Relationships are self-held unless noted. I = Immediate Family Member, Inst = My Institution. Relationships may not relate to the subject matter of this manuscript. For more information about ASCO's conflict of interest policy, please refer to www.asco.org/rwc or ascopubs.org/jco/site/ifc.

\section{Bo Jan Noordman}

No relationship to disclose

Mathilde G.E. Verdam

No relationship to disclose

Sjoerd M. Lagarde

No relationship to disclose

Maarten C.C.M. Hulshof

No relationship to disclose

Pieter van Hagen

No relationship to disclose

Mark I. van Berge Henegouwen

No relationship to disclose

Bas P.L. Wijnhoven

No relationship to disclose

Hanneke W.M. van Laarhoven

Research Funding: Bayer HealthCare Pharmaceuticals (Inst), BristolMyers Squibb (Inst), Eli Lilly (Inst), Roche (Inst), Philips Healthcare (Inst), Celgene (Inst), Nordic Group (Inst)

Grard A.P. Nieuwenhuijzen

No relationship to disclose

Geke A.P. Hospers

No relationship to disclose

Johannes J. Bonenkamp

No relationship to disclose

Miguel A. Cuesta

No relationship to disclose

Reinoud J.B. Blaisse

No relationship to disclose

Olivier R. Busch

No relationship to disclose

Fiebo J.W. ten Kate

No relationship to disclose

Geert-Jan M. Creemers

No relationship to disclose

Cornelis J.A. Punt

No relationship to disclose

\section{John Th.M. Plukker}

No relationship to disclose

Henk M.W. Verheul

No relationship to disclose

Ernst J. Spillenaar Bilgen

No relationship to disclose

Herman van Dekken

No relationship to disclose

Maurice J.C. van der Sangen

Travel, Accommodations, Expenses: Roche

\section{Tom Rozema}

No relationship to disclose

\section{Katharina Biermann}

No relationship to disclose

Jannet C. Beukema

No relationship to disclose

Anna H.M. Piet

No relationship to disclose

Caroline M. van Rij

No relationship to disclose

Janny G. Reinders

No relationship to disclose

Hugo W. Tilanus

No relationship to disclose

Ewout W. Steyerberg

Patents, Royalties, Other Intellectual Property: Royalties from Springer for book on prediction models

Ate van der Gaast

No relationship to disclose

Mirjam A.G. Sprangers

No relationship to disclose

\section{J. Jan B. van Lanschot}

Other Relationship: Dutch Cancer Foundation (KWF Kankerbestrijding), Coolsingel Stichting, Erasmus MC/MRace Fund 


\section{Appendix}

\section{Trial Design}

Details of this multicenter, randomized trial, have been reported previously. ${ }^{9,10,19}$ Briefly, patients with locally advanced (clinical stage T1N1M0 or T2-3N0-1M0 according to the 6th edition of the TNM cancer staging) ${ }^{26}$, histologically proven squamous cell carcinoma (SCC), adenocarcinoma (AC) or large-cell undifferentiated carcinoma of the esophagus or esophagogastric junction (EGJ) were eligible for inclusion. Eligible patients were between 18 and 75 years of age; had adequate pulmonary, hematological, hepatic and renal function; and a WHO performance score of 2 or better. The study protocol was approved by the institutional review boards and all patients provided written informed consent.

\section{Randomization}

Patients were randomized 1:1 to each treatment group, with random permuted block sizes of 4 or 6 . All patients were stratified according to treatment center, WHO performance score, histological tumor type and clinical lymph node status.

\section{Procedures}

Patients assigned to the nCRT group received carboplatin (AUC $2 \mathrm{mg} / \mathrm{mL}$ per $\mathrm{min}$ ) and paclitaxel $\left(50 \mathrm{mg} / \mathrm{m}^{2}\right.$ of body-surface area) intravenously for five cycles on days $1,8,15,22$, and 29. Concurrent radiation therapy of 41.4 Gy was given in 23 fractions of 1.8 Gy, 5 days per week. Patients in the surgery alone group received surgery as soon as possible, whereas those in the nCRT plus surgery group preferably had surgery 4 to 6 weeks after completion of nCRT. For carcinomas at or above the level of the carina, a transthoracic esophagectomy with two-field lymphadenectomy was performed. For carcinomas located well below the carina, either a transthoracic esophagectomy with two-field lymphadenectomy or a transhiatal esophagectomy with upper abdominal and lower mediastinal lymphadenectomy was performed, depending on patient characteristics and local preferences. For carcinomas involving the esophagogastric junction, a transhiatal esophagectomy was preferred. During the first year after completion of treatment, follow-up took place every 3 months. In the second year, patients were followed every 6 months and annually thereafter until 5 years after completion of treatment. Additional visits were scheduled if complaints arose before the next visit. ${ }^{9,10}$

\begin{tabular}{|c|c|c|c|}
\hline Parameter & Cohen's d* & $P$ & $95 \% \mathrm{Cl}$ \\
\hline Baseline scores for $\mathrm{nCRT}$ group & 0.56 & $<.001$ & 0.47 to 0.65 \\
\hline Difference for surgery alone & -0.04 & .598 & -0.18 to 0.10 \\
\hline \multicolumn{4}{|l|}{ Comparison with baseline } \\
\hline 1 week post-nCRT & -0.93 & $<.001$ & -1.12 to -0.74 \\
\hline 3 months postsurgery for $\mathrm{nCRT}$ group & -1.09 & $<.001$ & -1.29 to -0.90 \\
\hline Difference for surgery alone & 0.21 & .157 & -0.08 to 0.49 \\
\hline 6 months postsurgery for $\mathrm{nCRT}$ group & -0.70 & $<.001$ & -0.89 to -0.52 \\
\hline Difference for surgery alone & 0.01 & .968 & -0.27 to 0.28 \\
\hline 9 months postsurgery for $\mathrm{nCRT}$ group & -0.53 & $<.001$ & -0.72 to -0.35 \\
\hline Difference for surgery alone & -0.15 & .287 & -0.43 to 0.13 \\
\hline 12 months postsurgery for nCRT group & -0.51 & $<.001$ & -0.69 to -0.32 \\
\hline Difference for surgery alone & -0.05 & .717 & -0.34 to 0.23 \\
\hline \multicolumn{4}{|l|}{ Comparison with previous measurement } \\
\hline 3 months postsurgery for nCRT group & -0.16 & .164 & -0.38 to 0.07 \\
\hline 6 months postsurgery for nCRT group & 0.39 & $<.001$ & 0.24 to 0.54 \\
\hline Difference for surgery alone & -0.20 & .079 & -0.43 to 0.02 \\
\hline 9 months postsurgery for $\mathrm{nCRT}$ group & 0.17 & .022 & 0.02 to 0.32 \\
\hline Difference for surgery alone & -0.16 & .159 & -0.38 to 0.06 \\
\hline 12 months postsurgery for nCRT group & 0.03 & .730 & -0.14 to 0.19 \\
\hline Difference for surgery alone & 0.10 & .430 & -0.15 to 0.35 \\
\hline
\end{tabular}




\section{Noordman et al}

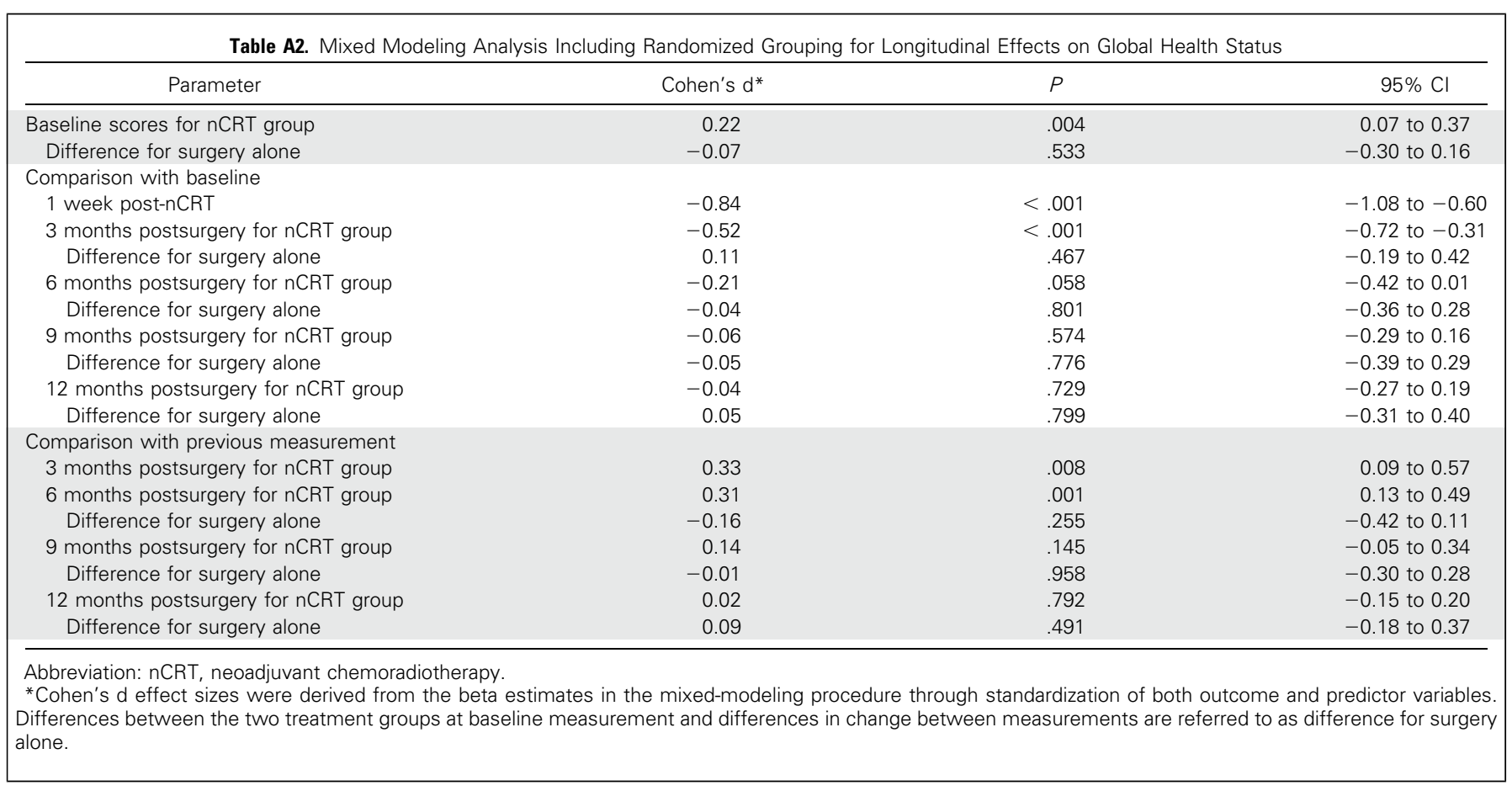

\begin{tabular}{|c|c|c|c|}
\hline Parameter & Cohen's d* & $P$ & $95 \% \mathrm{Cl}$ \\
\hline Baseline scores for nCRT group & -0.63 & $<.001$ & -0.76 to -0.49 \\
\hline Difference for surgery alone & 0.08 & .421 & -0.12 to 0.29 \\
\hline \multicolumn{4}{|l|}{ Comparison with baseline } \\
\hline 1 week post-nCRT & 1.45 & $<.001$ & 1.23 to 1.67 \\
\hline 3 months postsurgery for $n C R T$ group & 1.12 & $<.001$ & 0.91 to 1.32 \\
\hline Difference for surgery alone & -0.23 & .137 & -0.53 to 0.07 \\
\hline 6 months postsurgery for $\mathrm{nCRT}$ group & 0.74 & $<.001$ & 0.54 to 0.93 \\
\hline Difference for surgery alone & -0.14 & .331 & -0.44 to 0.15 \\
\hline 9 months postsurgery for $\mathrm{nCRT}$ group & 0.53 & $<.001$ & 0.34 to 0.72 \\
\hline Difference for surgery alone & 0.05 & .754 & -0.25 to 0.34 \\
\hline 12 months postsurgery for $n C R T$ group & 0.49 & $<.001$ & 0.31 to 0.68 \\
\hline Difference for surgery alone & 0.05 & .723 & -0.23 to 0.33 \\
\hline \multicolumn{4}{|l|}{ Comparison with previous measurement } \\
\hline 3 months postsurgery for $n C R T$ group & -0.33 & .002 & -0.54 to -0.12 \\
\hline 6 months postsurgery for nCRT group & -0.38 & $<.001$ & -0.54 to -0.22 \\
\hline Difference for surgery alone & 0.08 & .487 & -0.15 to 0.32 \\
\hline 9 months postsurgery for $\mathrm{nCRT}$ group & -0.21 & .010 & -0.37 to -0.05 \\
\hline Difference for surgery alone & 0.19 & .119 & -0.05 to 0.43 \\
\hline 12 months postsurgery for $\mathrm{nCRT}$ group & -0.03 & .656 & -0.19 to 0.12 \\
\hline Difference for surgery alone & 0.00 & .970 & -0.23 to 0.24 \\
\hline $\begin{array}{l}\text { Abbreviation: } \mathrm{nCRT} \text {, neoadjuvant chemorac } \\
{ }^{*} \text { Cohen's d effect sizes were derived from } \\
\text { Differences between the two treatment gro } \\
\text { alone. }\end{array}$ & $\begin{array}{l}\text { mixed-mode } \\
\text { tt and differ }\end{array}$ & $\begin{array}{l}\text { ndardiza } \\
\text { heasuren }\end{array}$ & $\begin{array}{l}\text { redictor variables. } \\
\text { erence for surgery }\end{array}$ \\
\hline
\end{tabular}




\begin{tabular}{|c|c|c|c|}
\hline Parameter & Cohen's d* & $P$ & $95 \% \mathrm{Cl}$ \\
\hline Baseline scores for $n C R T$ group & -0.09 & .262 & -0.26 to 0.07 \\
\hline Difference for surgery alone & 0.18 & .159 & -0.07 to 0.43 \\
\hline \multicolumn{4}{|l|}{ Comparison with baseline } \\
\hline 1 week post-nCRT & 0.32 & .001 & 0.14 to 0.50 \\
\hline 3 months postsurgery for nCRT group & 0.40 & $<.001$ & 0.19 to 0.61 \\
\hline Difference for surgery alone & -0.15 & .346 & -0.46 to 0.16 \\
\hline 6 months postsurgery for nCRT group & 0.14 & .215 & -0.08 to 0.36 \\
\hline Difference for surgery alone & -0.15 & .362 & -0.48 to 0.18 \\
\hline 9 months postsurgery for nCRT group & -0.14 & .218 & -0.37 to 0.09 \\
\hline Difference for surgery alone & 0.00 & .992 & -0.35 to 0.35 \\
\hline 12 months postsurgery for $\mathrm{nCRT}$ group & -0.14 & .210 & -0.36 to 0.08 \\
\hline Difference for surgery alone & -0.06 & .712 & -0.40 to 0.28 \\
\hline \multicolumn{4}{|l|}{ Comparison with previous measurement } \\
\hline 3 months postsurgery for nCRT group & 0.08 & .459 & -0.13 to 0.28 \\
\hline 6 months postsurgery for nCRT group & -0.26 & .006 & -0.45 to -0.07 \\
\hline Difference for surgery alone & 0.00 & .989 & -0.28 to 0.27 \\
\hline 9 months postsurgery for $n C R T$ group & -0.28 & .003 & -0.47 to -0.10 \\
\hline Difference for surgery alone & 0.15 & .295 & -0.13 to 0.43 \\
\hline 12 months postsurgery for $\mathrm{nCRT}$ group & 0.00 & .982 & -0.19 to 0.19 \\
\hline Difference for surgery alone & -0.06 & .675 & -0.36 to 0.23 \\
\hline
\end{tabular}

\begin{tabular}{|c|c|c|c|}
\hline Parameter & Cohen's d* & $P$ & $95 \% \mathrm{Cl}$ \\
\hline Baseline scores for $n C R T$ group & -0.10 & .294 & -0.28 to 0.09 \\
\hline Difference for surgery alone & 0.21 & .136 & -0.07 to 0.49 \\
\hline \multicolumn{4}{|l|}{ Comparison with baseline } \\
\hline 1 week post-nCRT & 0.47 & .001 & 0.21 to 0.72 \\
\hline 3 months postsurgery for nCRT group & 0.43 & .001 & 0.19 to 0.68 \\
\hline Difference for surgery alone & -0.25 & .177 & -0.61 to 0.11 \\
\hline 6 months postsurgery for nCRT group & 0.07 & .582 & -0.17 to 0.30 \\
\hline Difference for surgery alone & -0.15 & .403 & -0.50 to 0.20 \\
\hline 9 months postsurgery for nCRT group & -0.13 & .267 & -0.37 to 0.10 \\
\hline Difference for surgery alone & -0.19 & .283 & 0.55 to 0.16 \\
\hline 12 months postsurgery for $\mathrm{nCRT}$ group & -0.21 & .086 & -0.45 to 0.03 \\
\hline Difference for surgery alone & -0.05 & .774 & -0.42 to 0.31 \\
\hline \multicolumn{4}{|l|}{ Comparison with previous measurement } \\
\hline 3 months postsurgery for nCRT group & -0.03 & .816 & -0.30 to 0.23 \\
\hline 6 months postsurgery for $\mathrm{nCRT}$ group & -0.37 & $<.001$ & -0.53 to -0.21 \\
\hline Difference for surgery alone & 0.10 & .422 & -0.14 to 0.33 \\
\hline 9 months postsurgery for nCRT group & -0.20 & .022 & -0.37 to -0.03 \\
\hline Difference for surgery alone & -0.04 & .741 & -0.30 to 0.21 \\
\hline 12 months postsurgery for nCRT group & -0.08 & .280 & -0.22 to 0.07 \\
\hline Difference for surgery alone & 0.14 & .212 & -0.08 to 0.36 \\
\hline \multicolumn{4}{|c|}{$\begin{array}{l}\text { Abbreviation: } \mathrm{nCRT} \text {, neoadjuvant chemoradiotherapy. } \\
\text { *Cohen's d effect sizes were derived from the beta estimates in the mixed-modeling procedure through standardization of both outcome and predictor variables. } \\
\text { Differences between the two treatment groups at baseline measurement and differences in change between measurements are referred to as difference for surgery } \\
\text { alone. }\end{array}$} \\
\hline
\end{tabular}

